\title{
Antibacterial and Antioxidant Phenylpropanoid Derivative from the Leaves of Plantago lanceolate
}

Firew Deribew, Milkyas Endale* and Yadessa Melaku

Department of Chemistry, School of Applied Natural Sciences, Adama Science and Technology University, Adama, Ethiopia

*Corresponding author: Endale M, School of Applied Natural Sciences, Adama Science and Technology University, Adama, Ethiopia, Tel: +251934208852; E-mail: milkyasendale@yahoo.com

Received: March 05, 2018; Accepted: March 22, 2018; Published: April 02, 2018

Copyright: () 2018 Deribew F, et al. This is an open-access article distributed under the terms of the Creative Commons Attribution License, which permits unrestricted use, distribution, and reproduction in any medium, provided the original author and source are credited.

\begin{abstract}
Plantago lanceolata (Plantaginaceae) is a perennial cosmopolitan species traditionally used for blood clotting and healing of wound. The powdered leaves were successively extracted with n-hexane, ethyl acetate and methanol to give $1.55,2.16$, and $8.2 \%$, yield, respectively. Silica gel column chromatography afforded one phenylpropanoid derivative named verbascoside. The structure of the compound was determined using spectroscopic methods (UVVis, IR, NMR). The extracts, and verbascoside were evaluated invitro for antibacterial activities by using the disc diffusion method against Staphylococcus aureus, Escherichia coli, Klebsiella pneumania and Proteus miabilis. The promising inhibition zone $(20 \mathrm{~mm})$ was observed by verbascoside against $S$. aureus compared to standard Ciprofloxacin $(23 \mathrm{~mm})$. The radical scavenging activity of the methanol and ethyl acetate extract, and verbascoside compounds were $64.2 \%, 79.2$ and 83.9 , respectively suggesting that verbascoside displayed powerful radical scavenging activity indicating the potential of the plant as herbal remedies.
\end{abstract}

Keywords: Plantago; P. lanceolate; Verbascoside; Antioxidant; Antibacterial

\section{Introduction}

Natural products and their related moieties have historically been incredible as a source of therapeutic agents. The past century, however, has seen an increasing role played by microorganisms and marine organisms in the production of drugs for the treatment of serious diseases. Natural products will continue to play a crucial role in meeting this demand through the expanded investigation of the world's biodiversity, much of which remains unexplored [1]. Traditional remedies for wound healing also have a wide usage among the people living in the rural parts of Ethiopia. Several medicinal plants have been reported to be used for the treatment of wounds and ulcers [2]. Among these plants, Plantago species were reported to be used as wound healing agent with its severe, haemostatic and antimicrobial properties.

Plantago lanceolata (ribwort plantain) belonging to the genus Plantago and family Plantaginaceae is a perennial cosmopolitan species which shows high ecological plasticity, being found naturally in grassy areas on roadsides, in pastures and in crops as weeds. $P$. lanceolata is locally termed as "gurteb" in Amharic and "kortobe" in Afan Oromo (Ethiopia). Those Plantago is a genus of about 265 species of small, inconspicuous plants commonly called plantains. Previous studies have shown that Plantago species have analgesic, antiinflammatory, antimicrobial, antioxidant, hepatoprtective activities, and cytotoxic effect on the cancer cells [3]. Despite the traditional use of this plant against various diseases, to the best of our knowledge there is limited report on the chemical constituents, antibacterial and antioxidant studies of the leaves extract of this plant. Hence, the current study was undertaken primarily to isolates, characterizes compounds from the leaves of $P$. lanceolata plant and examine for antibacterial and antioxidant studies of the leaves extract and compounds.

\section{Materials and Methods}

\section{Plant material}

Fresh leaves of $P$. lanceolata were collected in November 2016 from Mugher town, Adea Berga Woreda, west shoa zone, Oromia, Ethiopia. The plant was authenticated by a botanist Shambel Alemu at the Biology Department of Addis Ababa University and specimen stored (Voucher no: F001/2016) in the National Herbarium of Ethiopia, Addis Ababa University, Addis Ababa, Ethiopia. The leaves were washed with water without squeezing to remove trash and dust particles and then air-dried at room temperature $\left(26^{\circ} \mathrm{C}\right)$ for one week. The air-dried leaves were chopped into small pieces and finally grounded using a mortar and weighed.

\section{Extraction and isolation}

Air dried leaves powder ( $300 \mathrm{~g}$ ) of $P$. lanceolata was first soaked in $\mathrm{n}$-hexane $(1.5 \mathrm{~L})$ for $72 \mathrm{~h}$ at room temperature. The mixtures were filtered and concentrated under reduced pressure at a temperature of $40^{\circ} \mathrm{C}$ using rotary evaporator to afford $4.65 \mathrm{~g}$ bright green crude extract. The marc was then extracted with ethyl acetate $(1.5 \mathrm{~L})$, after soaking for $72 \mathrm{~h}$ at room temperature. Then filtered and concentrated in rotary evaporator to furnish $6.5 \mathrm{~g}$ deep green crude extract. Finally the marc remaining was extracted using methanol following similar procedure and afforded $24.6 \mathrm{~g}$ of dark green crude extract. The methanol extract (13.6 g) was subjected to silica gel column chromatography (silica gel $150 \mathrm{~g}$ ) and eluted with increasing gradient of ethyl acetate in n-hexane. A total of 27 fractions were collected. Fractions 22-23 (2.35 g) were combined and further purified by column chromatography (Silica gel $40 \mathrm{~g}$ ) using methanol/Ethyl acetate 
Page 2 of 4

(5:95, isocratic mode) as eluent to give five fractions. Fraction 3 (66 $\mathrm{mg}$, compound 1) afforded compound 1.

\section{Antibacterial activity}

The EtOAc and methanol extracts of the leaves and verbascoside (1) were evaluated invitro for antibacterial activity by using the disc diffusion method against one gram positive bacterium Staphylococcus aureus (S. aureus) and three gram negative bacterium Escherichia coli, Klebsiella pneumania and Proteus miabilis. The bacterial cultures were inoculated into the Muller Hinton Agar (MHA). Ciprofloxacin was used as positive control. Approximately, $20 \mathrm{~mL}$ of sterile MHA were poured into sterile culture plates and allowed to set wells of about 6 $\mathrm{mm}$ in diameter which were punched on the plates. Standard solutions of $1.5 \mathrm{mg} / \mathrm{mL}$ concentration of the extracts and isolated compounds were prepared and $10 \mu \mathrm{L}$ solutions from the concentration were loaded to the discs in different replications. The plates were incubated at $37^{\circ} \mathrm{C}$ The antibacterial activity of the plant extracts were evaluated by measuring the zone of inhibition against the test organism after 24 hrs [4].

\section{Antioxidant activity}

DPPH assay: The free radical scavenging activity of the EtOAc, $\mathrm{MeOH}$ extract and isolated compounds were measured by $1,1-$ diphenyl-2-picryl-hydrazyl (DPPH) method [5]. With this method it is possible to determine the antiradical power of an antioxidant by measuring the decrease in the absorbance of DPPH at $517 \mathrm{~nm}$. As a result of the color changing from purple to yellow the absorbance is decreased when the DPPH radical is scavenged by an antioxidant through donation of hydrogen to form a stable DPPH-H molecule [6] Lower absorbance of the reaction mixture indicated higher free radical scavenging activity [7].
The EtOAc extract was dissolved in four vials containing methanol to give 500, 250, 125 and $62 \mu \mathrm{g} / \mathrm{mL}$. To each $1 \mathrm{~mL}$ of the above EtOAc extracts was added each $4 \mathrm{~mL}$ of $0.04 \% \mathrm{DPPH}$ which gave 100, 50, 25 and $12 \mu \mathrm{g} / \mathrm{mL}$. The resulting solution was placed in an oven at $37^{\circ} \mathrm{C}$ for 30 minutes and subjected to UV-Vis spectrophotometer to record absorbance at $517 \mathrm{~nm}$. This was repeated for the methanol extracts and isolated compounds. The absorbance of $0.04 \% \mathrm{DPPH}$ in $\mathrm{MeOH}$ solution was found to be 1.06 . The percentage DPPH inhibition was calculated according to the following formula [8].

$\%$ of radical scavenging activity $=A b_{\text {standard }}-A b_{\text {analyte }} / A b_{\text {standard }} \times 100$

\section{Results and Discussion}

Silica gel column chromatography of the leaf extract of Plantago lanceolata afforded one compound. The FT-IR spectrum displayed absorption bands at $3429 \mathrm{~cm}^{-1}, 1692 \mathrm{~cm}^{-1}, 1604 \mathrm{~cm}^{-1}$ and $2923 \mathrm{~cm}^{-1}$ attributed to hydroxyl moiety, $\alpha, \beta$-unsaturated carbonyl carbon, carbon-carbon double bond and methyl C-H stretching vibrations.

The ${ }^{1} \mathrm{H}$ NMR spectrum of compound 1 (Table 1) exhibited six aromatic protons $\left(\delta_{\mathrm{H}}\right.$ 7.20-6.58 region) with two sets of $\mathrm{ABX}$ multiplicity pattern, two trans-olefinic protons $(\mathrm{J}=15.99 \mathrm{~Hz})$, and a benzylic methylene at $\delta_{\mathrm{H}} 2.77(2 \mathrm{H}, \mathrm{t}, \mathrm{J}=7.39 \mathrm{~Hz})$ suggesting the presence of a caffeic acid unit and 3', 4'- dihydroxyphenethyl alcohol moiety. In addition, two anomeric proton signals at $\delta_{\mathrm{H}} 4.46(\mathrm{~d}, \mathrm{~J}=7.9$ $\mathrm{Hz})$ and $5.31(\mathrm{~d}, \mathrm{~J}=1.6 \mathrm{~Hz})$ were attributed to $\beta$-glucose and $\alpha$ rhamnose units, respectively, suggesting the presence of disaccharide moiety. The acyl group was positioned at the C-4" position of the glucose unit, on the basis of the deshielding of the $\mathrm{H}-4$ " signal $\left(\delta_{\mathrm{H}} 4.95\right.$ $\mathrm{t}, \mathrm{J}=9.4 \mathrm{~Hz}$ ) of the glucose unit. The methyl group of acetyl attached to the rhamnose was observed at $\delta_{\mathrm{H}} 1.98$ whereas methyl of the ethyl moiety attached to the glucose were observed at $\delta_{\mathrm{H}} 1.20$.

\begin{tabular}{|c|c|c|c|c|c|}
\hline Position & $\delta_{\mathrm{H}}$ & $\delta_{c}$ & Position & $\delta_{\mathrm{H}}$ & $\delta_{c}$ \\
\hline 1 & & 130.3 & $1 "$ & $4.46(1 \mathrm{H}, \mathrm{d}, \mathrm{J}=8.00)$ & 102.8 \\
\hline 2 & $6.78(1 \mathrm{H}, \mathrm{d}, \mathrm{J}=1.99)$ & 116 & $2 "$ & & 75.2 \\
\hline 3 & & 143.4 & $3 "$ & & 79.4 \\
\hline 4 & & 144.8 & $4 "$ & $4.94(1 \mathrm{H}, \mathrm{t}, \mathrm{J}=9.6,9.1)$ & 70.7 \\
\hline 5 & $6.74(1 \mathrm{H}, \mathrm{d}, \mathrm{J}=7.99)$ & 115.1 & $5 "$ & & 72.7 \\
\hline 6 & $\begin{array}{l}6.57 \\
(1 \mathrm{H}, \mathrm{dd}, \mathrm{J}=10.00)\end{array}$ & 120.2 & $6 "$ & $3.62(2 \mathrm{H}, \mathrm{m})$ & 61.4 \\
\hline 7 & $2.76(2 \mathrm{H}, \mathrm{m})$ & 35.3 & $\mathrm{CH}_{2} \mathrm{CH}_{3}$ & $3.64(2 \mathrm{H}, \mathrm{m})$ & 59.76 \\
\hline 8 & & 71.1 & $\mathrm{CH}_{2} \mathrm{CH}_{3}$ & $1.202(3 \mathrm{H}, \mathrm{t})$ & 13.6 \\
\hline $1^{\prime}$ & & 126.6 & $1^{\prime \prime}$ & $5.31(1 \mathrm{H}, \mathrm{d}, \mathrm{J}=1.6)$ & 100.9 \\
\hline $2^{\prime}$ & $7.21(1 \mathrm{H}, \mathrm{d}, \mathrm{J}=1.99)$ & 114.4 & $2 " \prime$ & & 71.3 \\
\hline $3^{\prime}$ & & 148.3 & 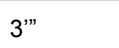 & & 69.4 \\
\hline $4^{\prime}$ & & 145.5 & $4^{\prime \prime \prime}$ & $4.82(1 \mathrm{H}, \mathrm{br})$ & 74.7 \\
\hline 5 & $6.89(1 \mathrm{H}, \mathrm{d}, \mathrm{J}=7.99)$ & 115.6 & $5^{\prime \prime \prime}$ & & 68.6 \\
\hline $6^{\prime}$ & $7.05(1 \mathrm{H}, \mathrm{dd}, \mathrm{J}=9.99)$ & 122.1 & $6 " '$ & $1.11(3 \mathrm{H}, \mathrm{d}, \mathrm{J}=5.99)$ & 17.6 \\
\hline
\end{tabular}


Page 3 of 4

\begin{tabular}{|l|l|l|l|l|l|}
\hline $7^{\prime}$ & $7.62(1 \mathrm{H}, \mathrm{d}, \mathrm{J}=16)$ & 146.3 & $\mathrm{CH}_{3} \mathrm{CO}$ & $1.97(3 \mathrm{H}, \mathrm{s})$ & 20 \\
\hline $8^{\prime}$ & $6.33(1 \mathrm{H}, \mathrm{dd}, \mathrm{J}=15.99)$ & 113.9 & $\mathrm{CH}_{3} \mathrm{CO}$ & & 170.3 \\
\hline
\end{tabular}

Table 1: Spectral data of compound 1.

The proton decoupled ${ }^{13} \mathrm{C}-\mathrm{NMR}$ spectrum (Table 1) with the aid of DEPT-135 (Appendix 4) revealed the presence of thirtythree carbon resonances of which eight are quaternary, eighteen methines, four methylenes and three methyl groups. The spectrum showed signal at $\delta_{\mathrm{C}} 170.3$ due to acetyl carbonyl carbon and $\delta_{\mathrm{C}} 166.4$ due to $\alpha, \beta-$ conjugated carbonyl carbon. The presences of four oxygenated aromatic carbons were evident at $\delta_{\mathrm{C}} 143.4,144.8,145.5,148.3$. The signal observed at $\delta_{C} 146.3$ is ascribed to the $\beta$-carbon of the $\alpha, \beta$ unsaturated carbonyl carbon. The spectrum also showed the presence of two sugar moieties at $\delta_{\mathrm{C}} 61.4,68.6,69.4,70.7,71.1,72.6,74.8,75.2$, $79.4,100.9$ and 102.8. Among these, the signal characteristics of anomeric carbons were appeared at $\delta_{\mathrm{C}} 100.9$ (C-1"') and 102.8 (C-1"). The methyl group of acetyl attached to the rhamnose was observed at $\delta_{\mathrm{C}} 20.0$, methylene and methyl of the ethyl moiety attached to the glucose were observed at $\delta_{\mathrm{C}} 59.8$ and $\delta_{\mathrm{C}} 13.6$, respectively. Another diagnostic signal due to methyl group was observed at $\delta_{\mathrm{C}} 17.6$ suggesting one of the sugar moieties as rhamnose. Signals corresponding to two monosaccharides were found bearing 4 "'-acetyl and 6"-O- ethyl group. Based on the above spectral evidence, compound 1 was found to be 6 "-O-ethyl- 4 "'-acetyl verbascoside (1, Figure 1).<smiles>CCOC=C1O[C@H](OCCc2ccc(O)c(O)c2)[C@@H](O)C(OC2O[CH+]C(OC(C)=O)C(O)[C@H]2O)C1OC(=O)/C=C/c1ccc(O)c(O)c1</smiles>

Figure 1: Structure of compound 1.
The antibacterial tests showed considerable antibacterial activity against the bacterial species used in the study. verbascoside (1) showed promising activity against the tested strains except for $K$. pneumoia. The methanol extract was found to inhibit $S$. aureus and $P$. miabilis compared with EtOAc extract. On the other hand, the EtOAc extract displayed better activity than the $\mathrm{MeOH}$ extract against $E$. coli and $K$. pneumonia. verbascoside (1) showed promising inhibition diameter $(20 \mathrm{~mm})$ against $S$. aureus as compared to standard drug $(23 \mathrm{~mm})$ (Table 2).

\begin{tabular}{|l|l|l|l|l|}
\hline \multirow{2}{*}{ Sample } & \multicolumn{4}{|l|}{ Types of bacteria with mean inhibition diameter (mm) } \\
\cline { 2 - 5 } & $\begin{array}{l}\text { S. } \\
\text { aureus }\end{array}$ & E. coli & $\begin{array}{l}\text { K. } \\
\text { pneumonia }\end{array}$ & Proteus miabilis \\
\hline Ethyl acetate extract & - & 8 & 8 & - \\
\hline Methanol extract & 7 & - & - & 8 \\
\hline Verbascoside & 20 & 13 & 7 & 9 \\
\hline Chloroform & - & - & - & - \\
\hline Ciprofloxacin & 23 & 21 & 19 & 24 \\
\hline
\end{tabular}

Table 2: Zone of bacterial growth inhibition diameter $(\mathrm{mm})$.

The ethyl acetate, methanol extracts and verbascoside (1) were examined for its radical scavenging activities. The DPPH radical scavenging activity was found to be $64.2 \%, 79.2,87.7$ and 83.9, respectively, at $100 \mu \mathrm{g} / \mathrm{mL}$ (Table 3). The $\mathrm{IC}_{50}$ values of the EtOAc, $\mathrm{MeOH}$, and verbascoside (1) were $36.6,-59.1$ and 76.1 , respectively. The result obtained was found to be promising as compared to ascorbic acid which is used as positive control with percent inhibition of radical by $97 \%$ at $100 \mu \mathrm{g} / \mathrm{mL}$. The promising activity of verbascoside (1) may be attributed to the presence of phenolic hydroxyl groups. The result suggests that the leaves of $P$. lanceolata can be used as a natural antioxidant.

\begin{tabular}{|c|c|c|c|c|c|c|}
\hline \multirow[t]{3}{*}{ Concentration } & \multicolumn{6}{|l|}{ samples } \\
\hline & \multicolumn{2}{|l|}{ EtOAc extract } & \multicolumn{2}{|l|}{ MeOH extract } & \multicolumn{2}{|l|}{ Verbascoside } \\
\hline & Absorbance & $\begin{array}{l}\% \\
\text { activity }\end{array}$ & Absorbance & $\begin{array}{l}\% \quad \text { scavenging } \\
\text { activity }\end{array}$ & Absorbance & $\begin{array}{l}\% \quad \text { Scavenging } \\
\text { activity }\end{array}$ \\
\hline 100 & 0.38 & 64.2 & 0.2 & 79.2 & 0.2 & 83.9 \\
\hline 50 & 0.45 & 57.5 & 0.3 & 76.4 & 0.3 & 76.4 \\
\hline
\end{tabular}


Citation: Deribew F, Endale M, Melaku Y (2018) Antibacterial and Antioxidant Phenylpropanoid Derivative from the Leaves of Plantago lanceolate. Nat Prod Chem Res 6: 315. doi:10.4172/2329-6836.1000315

Page 4 of 4

\begin{tabular}{|l|l|l|l|l|l|l|}
\hline 25 & 0.56 & 47.2 & 0.3 & 71.7 & 0.3 & 67.9 \\
\hline 12 & 0.62 & 41.5 & 0.5 & 57.5 & 0.4 & 60.4 \\
\hline
\end{tabular}

Table 3: \% scavenging activity of the extracts and isolated compounds of $P$. lanceolate.

\section{Conclusion}

For decades traditional medicines have been used and continue to be an alternative approach on treatment for various diseases. Currently, the growing interest of consumers in substances of natural origin in association with the increasing concern surrounding potentially harmful infections disease has directed to a rising interest in the use of plant extracts as functional ingredients in many pharmaceutical products. Silica gel column chromatography of the methanol extract furnished a phenylpropanoid derivative, verbascoside (1) which showed promising antibacterial activity against $S$. aureus and antioxidant activity. The findings support the traditional use of the plant to treat various infectious diseases.

\section{Conflict of Interest}

The authors declare that there is no conflict of interests regarding the publication of this paper.

\section{Acknowledgments}

Firew Derebew is thankful to Applied Chemistry Program, Adama Science and Technology University for offering PG opportunity. We are also indebted to Department of Chemistry, Addis Ababa University for access to spectroscopic instruments.

\section{Supporting Information}

UV-Vis, IR, ${ }^{1} \mathrm{H}$ NMR, ${ }^{13} \mathrm{C}$ NMR, and DEPT-135 spectral data of compound 1 are all included in supporting information for further reference.

\section{References}

1. Pawar HA (2014) Natural Product as a Source of Lead to the Design of New Drugs. Nat Prod Chem Res 2: 15.

2. Brown K, Phillips T (2010) Nutrition and wound healing. Clin Dermatol 28: 432-439.

3. Fons F, Gargadennec A, Gueiffier A, Roussel J, Andary C (1998) Effects of cinnamic acid on polyphenol production in Plantago lanceolate. Phytochem 49: 697-702.

4. Murai M, Tamayam Y, Nishibe S (1995) Phenylethanoids in the herb of Plantago lanceolata and inhibitory effect on arachidonic acid-induced mouse ear edema. Planta Medica 61: 479.

5. Egwaikhide P, Gimba C (2007) Analysis of the phytochemical content and anti- microbial activity of Plectranthus glandulosis whole plant. MiddleEast J Scien Res 2: 135-138.

6. Nishibe S, Tamayama Y, Sasahara M, Andary C (1995) A phenylethanoid glycoside from Plantago asiatica. Phytochem 38: 741-743.

7. Andrzejewska-Golec E, Swiatek L (1986) Badania Chemotaksonomiczne rodzaju Plantago II. Analiza frakcji fenolokwasow. Herba Polonica 32: 19-31.

8. Maksyutina N (1971) Hydroxycinnamic acids of Plantago major and P. lanceolata. Chem Nat Compo 7: 795. 